\title{
Feedback Measures as a Strategy for Student Support in Open Distance Learning: Can it Come to the Aid of Weary Student Teachers?
}

\author{
Bobo Segoe \\ Department of Curriculum and Instructional Studies \\ University of South Africa (UNISA) \\ segoeba@unisa.ac.za
}

Doi:10.5901/mjss.2013.v4n14p705

\begin{abstract}
One important means of ensuring the effectiveness of teaching in an ODL setting and even in face-to-face platform is through the provision of meaningful feedback comments from all parties involved. This paper sets out to examine feedback measures as a form of student support strategies in Open Distance Learning (ODL) for student teachers. The paper draws on experiences in upgrading the qualifications of primary school teachers involved in the National Professional Diploma in Education (NPDE) programme at the University of South Africa (UNISA). A qualitative approach and purposive sampling were adopted. Based on the data collected, it was concluded that feedback strategies are crucial in an ODL environment and therefore, have to be planned with the utmost care they deserve.
\end{abstract}

Keywords: Open Distance Learning; distance education; feedback strategies; student support; tutors; student teachers

\section{Introduction}

Tait (2000:289) defines student support as the range of services, both for individuals and for students in groups, which complement the course materials or learning resources which are uniform to all learners and which are often perceived as the major offering of institutions using ODL. A very broad definition is "the entire range of services and strategies employed in the presentation and delivery of courses aimed at assisting and enabling learners to comprehend fully, assimilate and master the skills and knowledge needed to achieve success in their studies" (Mays 2000:12). Services such as tutoring, technological media, counselling, peer-group support, administrative support and feedback measures mentioned by Ukpo (2006:253), are crucial in the context of distance education (DE) systems in both developed and developing countries.

Debates within an institution about who its ODL students are, or will be, provides the platform from which to analyse what they need in terms of student support. However, although this may sound obvious, it is surprising how quickly one can find (in one's own and other ODL systems) examples of practices which ignore current students' needs, or ineffective provision of student support which has not resulted from an analysis of who and where students actually are. Examples may include feedback measures which are negative, insufficient or not timely and which are therefore ineffective, as they do not satisfy students' needs. Providing quality feedback to distance-learning is particularly important because students have fewer opportunities to ask a tutor for clarification on his or her comments (Kasprzak, 2005:23). This study is based on the premise that institutional investigation of learner support can initiate more debates and may also lead to improvements in education practice, as well as giving ODL institutions the chance to review their feedback strategic plans and correct practices that are contrary to the plan.

\section{Background to the research based on literature study}

The NPDE teachers' course is a South African 360 credit qualification, on level 5 of the National Qualification Framework (NQF). It is a three year DE qualification programme that has been designed not only to upgrade the qualifications of teachers, but also to equip them with the professional competencies relating to teaching and learning in schools. UNISA was one of the higher education institutions which were requested to incorporate NPDE course in its curricula since 2002. The nature of the NPDE programme, the way in which the curriculum has been developed and the requirements for its implementation, have all necessitated quality feedback as a strategy for successful teaching and learning. Feedback in education may refer to an objective description of a student's performance intended to guide future performances (Brookhart 2008:56). NPDE course acknowledged feedback as a strategy that helps students to maximise their potential at different stages of development, raise their awareness of strengths and areas that need improvement 
and identify actions to be taken to improve performance. Parsloe (1995:150) contends that ODL students value feedback, especially when it is given by someone credible whom they respect as a role model for their knowledge, attitudes or competence. Failing to give feedback sends a non-verbal communication in itself, and can lead to mixed messages and false assessment by ODL students of their own abilities, as well as a lack of trust in the teacher (Parsloe 1995:157).

It is a truth universally acknowledged that feedback is vital for any student (Bedford 2007:1). Researchers have recognised for years the strength of its impact on learning and achievement (Hattie 2003; Vollmeyer \& Rheinberg 2005; Biggs \& Tang 2007). According to Bedford (2007:1), without quality feedback comments, distance education students may feel a bit disconnected and this may create a feeling of insecurity. Just like any other fruitful learning activity, feedback has to be well prepared and meaningful. Through constant and well-planned feedback strategies, NPDE students may feel more connected to the class, which in turn makes them more comfortable. Chetwynd \& Dobbyn (2011:67) confirm that in the ODL context, effective feedback on student assessment plays a vital role in retaining students and developing self-regulating learners, particularly in the first year of study.

According to Kintsch (2009:230), tutors in a DE setting must provide feedback that allows students to assess their current level of understanding and hints about what to do when their understanding is inadequate; and tutors must carefully select new texts to be studied that afford the students opportunities to learn more advanced strategies. For example, if tutors want to teach students how to summarise, they must give them sufficient feedback (either written or oral), about what they have written, hints on how to improve it and the opportunity to work on more and more difficult tasks. Using this content-based feedback, students not only improve the quality of their summaries, but the benefits will persist over time, even when students summarise without tutor support. Distance education, therefore, must provide learners with ample opportunity for guided practice or profound and corrective feedback. Wilkinson (2003:1) contends that corrective feedback is needed to enable learners to understand whether their attempts to improve their learning and experience have led to improvement.

Corrective feedback helps learners to realise errors and learn how to correct them by providing explicit and informative comments when students' marked work is returned.

Most DE institutions, as in the UK, use end-of-module questionnaires to gather feedback on learners' levels of satisfaction (Cowan 2002:6). This feedback from learners is equally as important and informative as the feedback that learners themselves receive, in that it helps tutors to improve their feedback strategies, which in turn enhances teaching and learning. The argument here is that a two-way feedback and communication are vital, particularly in a DE setting. Where a two-way communication is implicit in a feedback strategy, the atmosphere of developing a supportive and relaxed approach and mutual respect will be created. Kasprzak (2005:1) argues that mutual feedback is an indispensable part of the process of teaching in any learning context, but it seems to be more acutely sought after by DE learners, compared to their face-to-face counterparts. DE learners may be new to their environment and unfamiliar with the dynamics and organisation thereof. A socio-constructivist learning theory supported this study. Socio-constructivist theory claims that the personal construction of knowledge always occurs in social contexts, since learning activities are socially and contextually bound (Woolfolk 2007:481). The socio-constructivist theory also holds that learning occurs through interaction with other people and in specific settings. Furthermore, Wertsch (1997:28) argues that without social interaction with people in the immediate environment, such as feedback received from tutors or peers, it is always very difficult or almost impossible to acquire the real meaning of an important concept and to learn how to use it. Feedback, as a constructivist learning activity in an ODL setting, supports the students' interactions with their course materials, the construction and building of knowledge and the testing of this knowledge through interaction with other people such as peers and tutors. To this end, dialogue which comes in the form of feedback in socio-constructivist learning, is at the heart of ODL (Gravert 2005:137). It means that in an ODL context, there is a need to plan for effective feedback strategies or a dialogic space within which students engage with the content of the subject-matter and with the ideas of others (Mays 2010:31). Feedback comments have to be reciprocal, that is, from student to tutor and from tutor to student. Through reciprocal feedback, there will be continuous interaction between student and the tutor which ensures that the learning process is productive and successful. Du Plessis, Marais, Van Schalkwyk \& Weeks (2010:326) contend that socio-constructivists believe that learners are always confronted with complex educational situations, hence they need ample opportunities to engage in meaningful, problem-solving activities such as quality feedback comments.

\section{Research methodology}

In this article the researcher is seeking to answer two questions: What is the role played by effective feedback strategies in an ODL setting? as well as What are the perceptions of NPDE students about feedback measures used in their 
programme? Issues raised in this regard are the importance of well-planned feedback measures in an ODL mode as well as the attitudes of NPDE students towards the feedback measures used in their studies.

Out of a target population of 250 UNISA is a NPDE final-year students, 45 were purposefully selected as a sample from four NPDE contact-session centres, namely Durban, Nelspruit, Polokwane and Pretoria. The sample was representative of old and young teachers, males and females, those teaching in rural, semi-urban and urban areas and those teaching in Foundation, Intermediate and Senior Primary phases. The four contact-session centres catered for students coming from all over South Africa. The researcher had been an NPDE lecturer for seven years and therefore had complete access to all NPDE sites, and had also made informal observations with regard to feedback strategies used. All 45 students were exposed to the focus group interviews. Thereafter, eight students, who were selected from the same group, were further exposed to individual interviews. For individual interviews, two students were selected from each NPDE contact-session centre. An individual interview was used in order to obtain clarity on certain issues and gain more in-depth responses from the participants; it also enabled the researcher to delve deeper into the subject areas to obtain critical information.

The researcher identified a skilled scribe who took notes of the resolutions agreed upon by the members of the focus groups at each centre. This approach freed the researcher to concentrate on asking questions and do the necessary probing. However, during individual interviews, the researcher took notes himself. In this study an audio recorder was deliberately avoided, so as to ease tension in the participants and also to allow them to air their views as freely as possible. Final-year NPDE students were regarded as information-rich as they had been engaged in feedback activities in their course for about three years. Data was recorded and organised based on an interpretive approach, derived from Wolcott's (1993:9) categories of description, analysis and interpretation. This approach enabled descriptions to be developed through a process called coding, and thereafter themes were developed and analysed and the meanings of the data were subsequently interpreted (Hennink, Hutter \& Bailey 2011:227). The findings under each theme will be discussed later so as to answer the research questions as mentioned earlier.

The next step was to summarise and interpret the data collected. In interpretation, the researcher went beyond the descriptive data to extract meaning and insights from data based on a study of the literature and his own experience. The researcher examined all entries with the same code and then merged these themes and categories into patterns by finding links and connections among them. This process further integrated the data, and the researcher could then make statements about relationships in the data. In that way, the researcher confirmed information he already had, as this was supported by the data, and by so doing eliminated misconceptions.

\section{Research findings and discussion}

As mentioned earlier, the data analysis of this study identified five themes, namely negative feedback, insufficient feedback, timely feedback, corrective feedback and mutual feedback. Therefore, the discussions of the findings of the study will be based on each of the mentioned themes.

\subsection{Negative feedback}

Most participants in this study, in both focus groups and individual interviews, commented that their tutors did not give them motivating feedback, that is, feedback that clearly explains where and why learners have made errors and where and how they have to improve. In most cases, according to the participants, the feedback they received did not enhance learning as it was not positive, did not respond to specific aspects of their work and did not provide specific and clear suggestions for improving their own work. Tshaka (2011:9) contends that feedback comments must always be elaborate, constructive and motivating. This kind of feedback will extend the opportunity to teach by alleviating misunderstanding and will reinforce learning. In this manner, learner achievement will improve.

This study also found out that feedback given after marking students' assignments was, in some cases, negative or undermined students. Students indicated that tutors were not very sensitive or careful when commenting on certain mistakes. The golden rule about any feedback given, be it written or oral is that tutors should phrase their comments with caution. When highlighting principles of giving effective feedback, Parsloe (1995:149) suggests that the teacher should be very careful about the phrasing and wording used. Poor handling of any feedback strategy may result in the learners losing respect for and trust in the tutor, or in feedback being disregarded thereafter.

The focus groups from Pretoria and Nelspruit agreed that there were always "poor or no comments on marked assignments". When probed during individual interviews, participants associated the word "poor" with negative comments 
that were written by some tutors after marking their work. For example, one Nelspruit participant felt strongly that she failed the portfolio twice as a result of negative or "poor" feedback she received from the marker; the comments did not advise her correctly on how to rectify her mistakes. The statements by the participants above showed that feedback practices do not concur with what Tshaka (2011:6) advocates when she argues that written feedback, particularly on marked tasks, should always be constructive, unambiguous, elaborate and motivating. Moreover, this study strongly argues that feedback is valued when it is given by someone credible and whom the students respect as a role model.

Furthermore, one of the principles of providing positive feedback, according to Parsloe (1995:149), is that feedback should be regarded as being a delicate offer to the recipient; hence the tutor must be very sensitive to the impact of the message he or she is sending to the learner. Positive feedback, by its very nature, ought to acknowledge the learner's strengths and motivate him or her to work on areas of weakness. Any student wants and needs positive feedback to move forward in his or her career.

\subsection{Insufficient feedback}

In both the focus group and individual interviews, most participants felt that the feedback they received with their marked assignments was insufficient. Participants emphasised that markers merely gave ticks and allocated a mark without the necessary feedback. NPDE participants further commented that sometimes when they obtained a particularly high or low mark, there were no feedback remarks to justify such a mark.

It was evident from the above information that NPDE students needed comments that were informative and sufficient. For instance, it would appear that students were more interested in informative and sufficient feedback than in the marks they obtained. The majority of the NPDE participants in individual interviews supported the views expressed by participants in the focus groups. During focus-group interviews students agreed that they received either no or insufficient feedback from tutors on their marked tasks or assignments. In addition, participants said that they could not see the value of the mark because they did not know how they obtained it. In this regard, a group from Durban identified as a deficiency "insufficient feedback or comments after marking our assignments". In support of this sentiment, participants from Polokwane had this to say: "No sufficient comments on marked assignments in some modules".

This finding confirms the researcher's own experience as a former NPDE lecturer, that in most cases, learners used to complain that some markers did not allocate appropriate marks to them and that the comments like "Good" are not sufficient and did not tell them anything. Once feedback comments are informative, they will help the learner to realise his or her mistakes and where to improve.

\subsection{Timely feedback}

In the focus-group interview data, some participants stated that they did not receive any feedback from the markers, or that in some instances the feedback arrived late, that is, after they had written the examinations. For feedback to be effective, it has to be timely. Delay in providing learner feedback diminishes its value for learning. This fact is emphasised by Parsloe (1995:149) who states that "feedback must be timely and therefore the teacher should give feedback as soon after the event as possible". Prompt feedback will go a long way to cementing the relationship between a learner and a teacher. For example, if students receive feedback no more than a day after a test or homework assignment has been handed in, it will improve the relationship between the tutor and the student and also increase the students' window of opportunity to learn. However, participants from Pretoria indicated that they did receive their marked assignments in time. This could be attributed to the fact that all assignments were marked by external and internal Unisa markers who resided around Pretoria. Obviously, Pretoria students received their assignments earlier than their counterparts in, for example, Durban or Nelspruit. Finally, participants stated that in some modules, there were some NPDE markers who marked and returned the assignments within specified periods and others who failed to meet deadlines.

\subsection{Corrective feedback}

Wilkinson (2003:1) contends that corrective feedback is vital, as it enables learners to understand whether their attempts to improve their learning and experience have led to improvement. From the data collected, it became clear that the majority of the participants did not receive corrective feedback from tutors. Participants stated that in most cases feedback received did not count and did not give guidance on how to rectify mistakes committed.

A noteworthy finding is that most participants indicated that in some instances, written feedback was too 
generalised and was not related to specific facts and observations. In this case, DE students can feel totally disconnected and can be left wondering how to approach their work and how to progress. Corrective feedback should improve learning and equally be responsive to specific aspects of the student's work, such as test or homework answers, and therefore should provide specific and related suggestions. It is not terribly helpful for a tutor to say "Your work is sloppy". It is much more useful to describe the specific element of work that concerns the lecturer. There needs to be a strong link between the student's response and the lecturer's comments, and comments should always be instructive and corrective in nature.

\subsection{Mutual feedback}

Participants in the study agreed that in their NPDE studies, feedback was a one-way process, from the tutors to the students. For example, participants highlighted that they were not given a chance to reflect on the contents of study materials, let alone on the comments they got on their marked assignments. In my experience as a former NPDE tutor, there is little time for students to give feedback on their studies or marked assignments. During contact sessions, which were very short, tutors mainly concentrated on trying to "cover the syllabus" and mostly overlooked the use of feedback as a form of support strategy.

The researcher contends that in any ODL setting, the provision of two-way communication is of utmost importance as it builds a good rapport between a learner and a tutor (Hein-Nieminen 1995:251). Furthermore, this study argues that effective feedback is a result of the overall dialogue or interaction between the teacher and the learner or the learner and the learner, not a one-way communication. Bedford (2007:3) and Chetwynd \& Dobbyn (2011:56) claim that learning becomes effective when students can work collaboratively and in dialogue with one another. This means that enough opportunities must always be created for students to provide feedback to other students; compare their work to the stated criteria amongst themselves; ask questions after receiving feedback; try again and get it right.

\section{Recommendations}

Tutors who use effective feedback to help ODL students evaluate the students' abilities honestly and teach them how to capitalise on their strengths and compensate for their weaknesses foster intrinsic motivation (Masitsa, 2008:85). This study has demonstrated that overly negative feedback is discouraging because it destroys students' confidence, selfesteem and desire to improve on their work. Daniels \& Arapostathis (2005:35) contend that students with low self-esteem are not able or willing to undertake academic challenges which are crucial in any teaching and learning situation. Students are also discouraged by teachers who humiliate them through negative feedback. To this end, feedback as a teaching and learning strategy, particularly in an ODL environment, should be regarded by all as a crucial learner-support measure and should be planned and exercised with the care and importance it deserves. ODL tutors should be encouraged to give positive and corrective remedial comments at all times, even if a student has not performed well.

Students must be encouraged by course tutors to give feedback comments pertaining to mark allocation and on feedback given by a tutor on their marked tasks. To accomplish this, at the end of the semester or the academic year, learners should be given an opportunity to evaluate the entire course and give written comments on aspects such as tutor marking, course outcomes, learning resources or exam challenges. This can be done by sending learners an openended questionnaire to complete. The feedback responses from students must be analysed effectively with the view to bringing about the necessary changes and improvements to feedback as a teaching and learning strategy. This will ensure a two-way or a mutual feedback activity which is vital, particularly in an ODL mode of operation.

Tutors should keep feedback simple. When planning feedback, a tutor should decide on a small number of areas that he or she intends to cover and not merely create a "shopping list" of faults that could overwhelm and discourage the student. If a student commits a comedy of errors, or is falling behind in his or her work, a tutor should not automatically assume the student lacks commitment. Feedback should always be given on a timely basis. Since learning and studying require committed effort, through timely feedback students will be motivated to learn and study the knowledge and skills being taught. Unmotivated students exhibit behaviour which ranges from frustration, boredom, a lack of interest in learning and studying to fear that they may not be able to succeed (Masitsa, 2008:88). Furthermore, they do not perform in accordance with their innate potential, but underachieve. Clear turn-around time for each task given to students should be specified to each marker. All markers, therefore, should adhere to deadlines so that students cannot receive feedback late. It is not helpful to provide feedback about a particular behaviour long after the behaviour has occurred. 


\section{Conclusion}

The focus of this study was on the importance of effective feedback for students, particularly under-qualified teachers upgrading their qualifications through the mode of ODL. The findings also revealed the views and perceptions of NPDE students about feedback strategies used throughout their study career. Literature study argues that feedback is more sought-after by ODL students than by their face-to-face counterparts. The results suggest that failing to give effective feedback to ODL students can lead to mixed messages and false assessment by the students of their own abilities, as well as lack of respect for and trust in the tutor.

Feedback responses from tutors provide structure and direction, and are a means of prompting and getting full participation and feedback from the students. Feedback responses are not used to "lecture" per se, but rather to encourage improvement and generate participation and further discussion in a more effective manner than in a mere discussion format. As a result, feedback should influence the quality of students' learning in such a way that they learn optimally, as well as being well prepared for examinations. This study further revealed that interaction by means of written feedback comments on assignments is an essential element of ODL students' academic performance. It plays a crucial role in opening and maintaining dialogue between students and tutors.

\section{References}

Bedford, A. 2007. Providing feedback to students. CES Analysis Project. Available at: mhtml:file://C:IDocuments and SettingsITemporary Internet $F$ (accessed on 25 February 2011).

Biggs, J \& Tang, C. 2007. Teaching for quality learning at university. Berkshire: Open University Press.

Brookhart, SM. 2008. How to give effective feedback to your students. Alexandria: Association for Supervision and Curriculum Development.

Chetwynd, F \& Dobbyn, C. 2011. Assessment, feedback and marking guides in distance education. Open Learning 26(1):67-78.

Cowan, J. 2002. Eliciting student feedback from structured group sessions. Oxford: Oxford Brookes University.

Daniels, E \& Arapostathis, M. 2005. What do they want? Students' voices and motivation research. Urban Education 40(34):3-59.

Du Plessis, EC, Marais, P, Van Schalkwyk, A \& Weeks, F. 2010. Adapt or die: The views of Unisa student teachers on teaching practice at schools. Africa Education Review 7(2):323-341.

Gravett, S. 2005. Adult Learning: designing and implementing learning events - a diologic approach. $2^{\text {nd }}$ edition. Pretoria: Van Schaik.

Hattie, JA. 2003. "Teachers make a difference: hat is the research evidence?" Paper presented at ACER Research Conference, Melbourne. Available at: http:///www.acer.educ.au/document/RC2003_Hattie_teachersMakeADifference.pdf (accessed on 21 July 2010).

Hein-Nieminen, I. 1995. The postmodern learning environment, one world, many voices. 17th World Conference for Distance Education. California: Unpublished Paper.

Hennink, M, Hutter, I \& Bailey, A. 2011. Qualitative research methods. Los Angeles: Sage.

Kasprzak, J. 2005. Providing student feedback in distance education courses. An online learning magazine for UMUC Faculty. Washington, DC: The National Defence University.

Kintsch, W. 2009. Learning and constructivism, in Constructivist instruction: success or failure? edited by T Sigmund \& TM Duffy. New York: Routledge.

Masitsa, GM. 2008. Tracing the development of poor student motivation and performance in township secondary schools. Africa Education Review 5(1):84-108.

Mays, T. 2000. Learner support: a South African programme perspective. Open Learning through Distance Learning 6(2):11-28.

Mays, T. 2010. Conceptualising student support at Unisa. Discussion Document No. 4 in consultation with SAIDE Education Staff: Unpublished document. Pretoria: Unisa.

Parsloe, E. 1995. Coaching to handle customers' problems. 1st edition. London: Fenman Limited.

Tait, A. 2000. Planning student support for open and distance learning. Open Learning 15(3):287-299.

Tshaka, N.N. 2011. Providing Feedback to Students. A presentation made at The Tutor Development Workshop. Port Elizabeth: Unpublished Paper.

Vollmeyer, R \& Rheinberg, F. 2005. A surprising effect on learning. Learning and Instruction 15(6):589-602.

Ukpo, EO. 2006. Support for distance learners in a Nigerian distance education programme. Open Learning 21(3):253-261.

Wertsch, JV. 1997. Vygotsky and the formation of the mind. Cambridge: Cambridge University Press.

Wilkinson, SJ. 2003. Improving students in dissertation research through feedback studies. The Sheffield Hallam Building Surveying Experience. Sheffield: Hallam University.

Wolcott, H. 1993. Description, analysis and interpretation in qualitative inquiry. Thousand Oaks: Sage.

Woolfolk, A. 2007. Educational psychology. 10"th edition. New York: Pearson. 